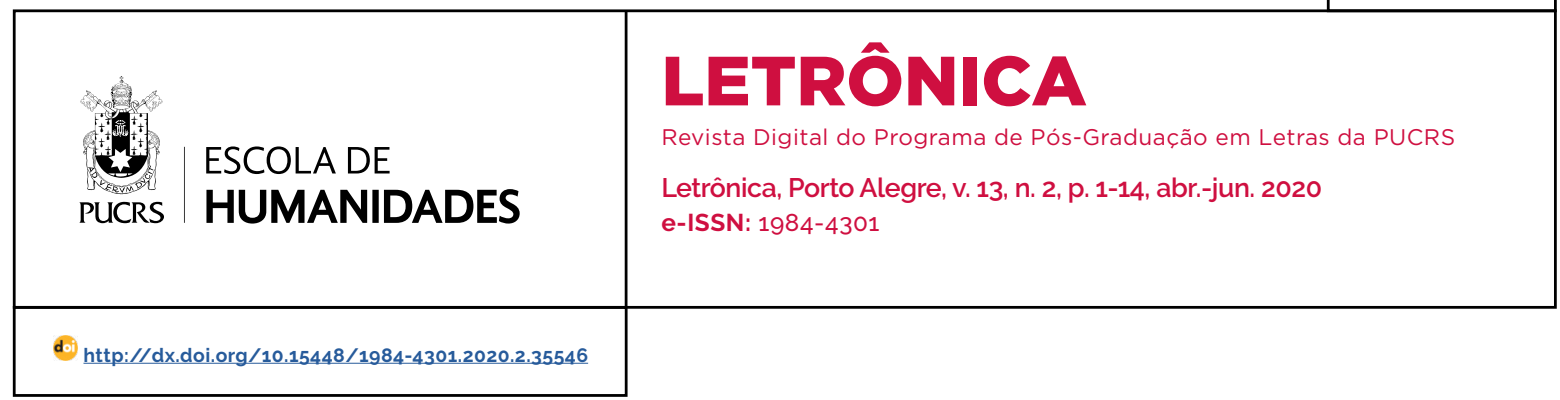

\title{
Fake news e pós-verdade na construção do Neoconservadorismo no Brasil pós-2013 e os efeitos nas eleições de 2018
}

\author{
Fake news and post-truth in the construction of neoconservatism in post-2013 Brazil \\ and the effects on 2018 elections
}

\section{Mauri de Castro \\ Azevedo ${ }^{1}$ \\ orcid.org/0000-0003-3036-6655 \\ maurijornalista@gmail.com}

\section{Marcus Antônio Assis \\ Lima $^{1}$}

orcid.org/0000-0001-8407-1866

malima@uesb.edu.br

Recebido em: 4 set. 2019

Aprovado em: 15 dez. 2019.

Publicado em: 13 ago. 2020.
Resumo: A conjuntura politica brasileira recente efetivou o recrudescimento do conservadorismo, especialmente no que diz respeito ao comportamento de uma parcela considerável da população que, ao abraçar ideias da extrema-direita, contribuiu para levar o Brasil a uma situação obscurantista. Diante da relevância dessa temática na atualidade, este estudo tem por objetivo desenvolver uma discussão sobre o crescimento das ideias extremistas sob a influência das fake news na era da pós-verdade. Metodologicamente é conduzido pela abordagem qualitativa de caráter exploratório e descritivo, à luz dos preceitos teóricos encontrados em Marcondes Filho (1989), Tandoc, Lim e Ling (2017), Dunker (2017), Gomes (2018), Löwy (2015), Miguel (2018), Almeida (2018), Souza (2016) e Charaudeau (2016), e apresenta uma discussão sobre a intolerância política nas redes sociais virtuais durante as eleições presidenciais de 2018. Como resultado desse cenário e com base no referencial utilizado, verificamos que a extrema-direita utilizou o ódio como plataforma política para manipular a opinião pública. Com efeito, o País registrou uma reconfiguração do sentido da vida politica nas instâncias de poder e cidadã. Palavras-chave: Política. Ódio. Intolerância. Pós-verdade. Fake news.

Abstract: The recent Brazilian political conjuncture has brought about a resurgence of conservatism, especially with regard to the behavior of a considerable portion of the population which, by embracing far-right ideas, has helped to bring Brazil into an obscurantist situation. Given the relevance of this theme today, this study aims to develop a discussion about the growth of extremist ideas under the influence of fake news in the post-truth era. Methodologically this study is conducted by the qualitative approach of exploratory and descriptive character in the light of the theoretical precepts found in Marcondes Filho (1989), Tandoc; Lim e Ling (2017), Dunker (2017), Gomes (2018), Löwy (2015), Miguel (2018), Almeida (2018), Souza (2016) and Charaudeau (2016), and present a discussion on political intolerance in social networks. during the 2018 presidential election. As a result of this scenario and based on the framework used, we find that the far right used hatred as a political platform to manipulate public opinion. Indeed, the country registered a reconfiguration of the meaning of political life in the instances of power and citizenship.

Keywords: Politics. Hate. Intolerance. Post-truth. Fake news.

\section{Introdução}

O recrudescimento do conservadorismo na política brasileira acarretou um debate público marcado pela retórica da violência, especialmente nas discussões provenientes das interações em redes sociais virtuais. A civilização tecnológica da sociedade em rede de Manuel Castells (2009) experimenta o convívio paradoxal entre aqueles que atuam pela liberdade e o desenvolvimento da sociedade, e sujeitos que permeiam o espaço virtual com a guerra e a desumanização a serviço da barbárie civilizatória, como sugere Theodor Adorno (1995). 
Enquanto as falsas informações circulam nos espaços cibernéticos em alta velocidade, observamos o surgimento e o crescimento de inúmeras falsas narrativas como as que negam o aquecimento global, o Holocausto nazista ou ainda as correntes que pregam a antivacinação e a esdrúxula Teoria Terraplanista sobre a qual a superficie do planeta Terra seria plana e não esférica.

Neste trabalho discutimos a intolerância política com o intuito de contribuir com uma reflexão que corrobore com valores democráticos capazes de proporcionar mudanças no exercício da política. Amparamos a nossa concepção ao constatar que o panorama instalado no Brasil contemporâneo, registra cada vez mais rompimentos de relacionamentos, seja no espectro virtual ou na aparência física cotidiana (LEVY, 1999) dos individuos. Assim, este estudo é oportunizado perante o momento do avanço da ideologia neoconservadora e o desafio de intervir na realidade com a perspectiva de manter acesa a esperança da transformação social e de um país socialmente mais igualitário.

No que diz respeito à estrutura, este trabalho está ordenado da seguinte maneira: na primeira seção apresentamos a definição do que é notícia para, em seguida, apontarmos o que hoje são consideradas fakes news, exemplificadas nas categorias fabricação e manipulação; na seção seguinte, perpassamos pela conceituação do significado da pós-verdade; prosseguindo, ilustramos o discurso de ódio neoconservador nas redes sociais virtuais identificado pós-2013 até as eleições de 2018, desenvolvendo uma análise do discurso com base na Teoria Semiolinguistica. Finalmente, pontuamos que, combinados, esses elementos alteraram o debate público com base na personalização de algoritmos formadores das "bolhas ideológicas", sugerindo a manipulação da opinião pública.

O desenvolvimento deste artigo acontece com a discussão geral da temática categorizada em subtemas de modo a aprofundar a compreensão. Assim, conduzimos este trabalho à luz dos preceitos teóricos encontrados em Marcondes Filho (1989), Tandoc, Lim e Ling (2017), Dunker
(2017), Gomes (2018), Löwy (2015), Miguel (2018), Almeida (2018), Souza (2016) e Charaudeau (2016). Empregamos a metodologia de pesquisa bibliográfica e exploratória baseada em publicações impressas e digitais, cuja busca online nas ferramentas Google, Scielo e Portal de Periódicos da Coordenação de Aperfeiçoamento de Pessoal de Nivel Superior (Capes) pesquisaram pelos termos "pós-verdade", "fake news" e "discurso de ódio".

\section{Fake news: desconstruindo fatos e disseminando ódio}

Produto das invenções tecnológicas do século $X V$ como a imprensa de Gutemberg, o jornalismo da Idade Moderna não se preocupava em relatar os fatos com a precisão e a objetividade convencionadas nas sociedades contemporâneas. Até o início do século XIX os jornais ocupavam-se em propagar informações relacionadas às causas politicas que agitavam a sociedade moderna. As notícias eram marcadas pelo tom panfletário e a retórica se sobressaia perante a descrição dos fatos quer fossem verdadeiros ou não. Com o passar do tempo os jornais de caráter opinativo foram progressivamente rejeitados enquanto as notícias se transformaram em produto mercadológico disponivel para comercialização. Emerge, assim, um novo jornalismo.

Esse novo jornalismo evoluiu com o surgimento e a expansão do sistema capitalista industrial norteado, especialmente, pelos avanços tecnológicos e, gradativamente, os jornais conquistaram autonomia financeira e política para serem transformados em um negócio rentável. É nesse contexto de mudança de paradigma e tecnológica que a notícia se torna um produto para venda, cada vez mais aperfeiçoado com o emprego de técnicas e de dinâmicas que garantissem dividendos aos proprietários dos jornais, agora administradores de empresas. Diante dos inúmeros fatos que ocorriam. era preciso otimizar a produção, garantido o aproveitamento dos fatos e a rentabilidade financeira. Desta maneira, a produção da notícia se adapta ao novo sistema econômico. 
Em uma conceituação crítica, Marcondes Filho (1989, p. 13) descreve que a notícia é "[...] aquilo que é anormal, mas cuja anormalidade interessa aos jornais como porta-vozes de correntes politicas [...]". Essa definição esclarece que nem toda anormalidade pode ser transformada em notícia, mas apenas a situação anormal em que seja possivel um uso político. Esse estudioso aponta ainda que "[... notícia é a informação transformada em mercadoria com todos os apelos estéticos, emocionais e sensacionais [...]" (1989, p. 13). Desta maneira, de modo a garantir a notícia como um produto visualmente consumivel, a informação é lapidada e adaptada "[...] às normas mercadológicas de generalização, padronização, simplificação e negação do subjetivismo [...]" (1989, p. 13).

A notícia produzida pelo jornalismo profissional e comercial continua obedecendo a critérios e a componentes para que seja passível de consumo. Essa lógica é analisada pelo italiano Mauro Wolf que considera os critérios de noticiabilidade como sendo um "[...] conjunto de elementos através dos quais o órgão informativo controla e gera a quantidade e os tipos de acontecimentos, de entre os quais há que selecionar as notícias [...]" (WOLF, 1999, p. 85). Segundo o estudioso italiano, os jornais indicam a existência de quatro critérios "valores-notícias" na produção da notícia, quais sejam: pressupostos implícitos ou considerações relativas às caracteristicas substantivas das notícias; conteúdo; disponibilidade do material e aos critérios relativos ao produto informativo; e, finalmente, público e concorrência.

Os quatro critérios não são uma classificação abstrata e operam de maneira peculiar. Segundo Wolf (1999), a primeira categoria se refere à transformação do acontecimento em notícia; a segunda dá conta do conjunto dos processos de produção e de realização; enquanto a terceira diz respeito à imagem formada pelos jornalistas sobre os destinatários; e, por último, a quarta, que trata das relações entre os mass media existentes no mercado informativo. Esses "valores-notícias" são flexiveis e no contexto do webjornalismo o fato é transformado em notícia sem limite de espaço e de tempo como ocorre, por exemplo, na rotina produtiva dos veículos impressos devido aos limites de espaço. Os hiperlinks possibilitam explorar o acontecimento com a máxima profundidade necessária e possivel.

Nesse novo cenário tecnológico a produção da notícia se descentralizou e, diante da infinitude de sites e blogs noticiosos, inúmeras versões sobre um acontecimento podem ser construidas em conformidade com a perspectiva e o interesse do "produtor da notícia". Ao instaurar a lógica da horizontalidade, a internet permitiu que o "produtor de notícia" desprezasse a apuração do fato e abolisse os "valores-notícias" posto que não possui compromisso com o rigor jornalístico por não ser profissional devidamente preparado para a elaboração da notícia.

Por outro lado, deturpação dos fatos, manipulação das informações ou mesmo "barrigadas"2 sempre estiveram presentes ao longo da história do jornalismo com o intuito de controlar a opinião pública. Nos tempos atuais, o ciberespaço (LEVY, 1999) experimenta o crescimento vertiginoso da produção e do compartilhamento de notícias, quer sejam verdadeiras ou não, que tendo em vista o tom panfletário e acusatório, no aspecto estético, regrediram ao período de nascimento do jornalismo. A facilidade de acesso às mais variadas ferramentas de produção e de publicação de conteúdo incorreu na recente onda de notícias falsas disseminadas no ambiente virtual. Essa onda se popularizou em torno da expressão fake news e tem sido estrategicamente utilizada como ferramenta de manipulação do debate público em um cenário marcado pelo irracionalismo.

Nesse sentido, as fakes news podem ser consideradas como sendo notícias falsas deliberadamente produzidas para causar prejuizos à imagem de um alvo pré-estabelecido quer seja um adversário político, um concorrente comercial ou mesmo um inimigo pessoal que, em tempos de interconectividade viraliza via

\footnotetext{
2 Barrigada é uma expressão comum ao jornalismo e diz respeito à publicação de uma informação falsa, por falta de checagem, sem que haja a intenção de enganar o leitor. Não se trata da terminologia fake news.
} 
plataformas digitais em formato midiatizado de texto, imagem, áudio ou vídeo. Os produtores de fake news encontraram nas redes sociais virtuais o potencial para fazê-las "viralizar" e alcançar os objetivos estrategicamente traçados.

O retorno financeiro é um elemento relevante que em muito contribui para impulsionar a propagação de fake news. A monetização de sites oferece a oportunidade para que os responsáveis por websites ganhem dinheiro diretamente em suas contas bancárias com base na inserção de anúncios, venda de produtos e a geração de tráfego/redirecionamento para outros sites. A propagação das fake news também é uma ação estrategicamente pensada por organizações criminosas que agem na internet coletando dados pessoais e informações financeiras indevidamente para a aplicação de golpes cibernéticos. Os golpistas utilizam de notícias alarmistas e falsas para chamar atenção e atrair o clique de internautas e dai instalarem programas maliciosos em computadores e dispositivos móveis. Nas relações sociais, os conteúdos enganosos em formato de fake news também são produzidos e difundidos em grande escala para incentivar o discurso de ódio materializado em preconceito e discriminação, especialmente, contra as diferenças e as minorias.

Igualmente como faz o jornalismo ao estabelecer uma chamada atrativa em busca audiência para seus produtos, os sites de cliques monetários descobriram nos títulos a fórmula para atrair e aumentar o fluxo de navegantes. Foi com essa perspectiva que jovens da cidade de Veles, na Macedônia, promoveram uma verdadeira enxurrada de fake news durante as eleições presidenciais americanas no ano de 2016 conforme relatou a BBC News. ${ }^{3}$ Depois do êxito em cativar internautas para os sites caça-cliques ${ }^{4}$ de monetização, as fakes news adquiriram novas funções que impossibilitam aos internautas comuns e desatentos discernirem entre verdadeiro e falso. E assim estabelecem a desinformação generalizada na esfera política.

Com efeito, a dimensão atribuida às notícias falsas foi ampliada e o universo semântico do termo adquiriu novos sentidos passando a designar uma contraposição a conteúdos que desagradam, como recorrentemente fazem o presidente norte-americano, Donald Trump, desde 2016, e, mais recentemente, o brasileiro, Jair Bolsonaro, na tentativa de desqualificar informações e desacreditar jornalistas e oposicionistas. Tudo que não agrada é classificado pejorativamente como fake news. Desta forma, a expressão tem sido empregada como subterfúgio estratégico para reprovar conteúdos, colocar em suspeição um fato alegando ser falso ou ainda para interpretar acontecimentos convenientemente às emoções, crenças e opiniões subjetivas. Nas eleições brasileiras de 2018 a terminologia foi amplamente empregada, tanto para atacar adversários quanto para classificar acontecimentos como falsos.

No intuito de aprofundar as pesquisas sobre a terminologia, os acadêmicos norte-americanos Tandoc, Ling e Lim (2017) analisaram 34 artigos científicos publicados entre os anos de 2003 e 2017 que utilizaram a expressão fake news. Como resultado, os pesquisadores identificaram ao menos seis formas de operacionalização das notícias falsas distribuídas em sátira, paródia, fabricação, manipulação, publicidade e propaganda (TANDOC; LIM; LING, 2017). Essa classificação oferece uma distinção que contribui para compreender como as fakes news são operacionalizadas no nivel de factualidade e na capacidade de enganar (TANDOC; LIM; LING, 2017). Neste artigo, nos interessa discutir os gêneros "fabricação" e "manipulação" posto que essas duas categorias prevaleceram dentre as notícias falsas que circularam nas eleições de 2018.

De um lado as fake news de "Fabricação" são notícias fabricadas com a intenção de desinformar a sociedade. Não apresentam base factual, geralmente possuem narrativas com viés político, são publicadas em sites com as mesmas

\footnotetext{
3 Disponivel em: https://www.bbc.com/portuguese/internacional-38206498. Acesso em: 9 abr 2019.

4 São sites clickbait ou caça clicks cujo conteúdo é duvidoso e extremamente sensacionalista com o objetivo de atrair a atenção e o acesso do internauta à página no intuito de auferir lucros através da publicidade.
} 
características e estilo de sites noticiosos para passar credibilidade e criar legitimidade. No entanto, possuem baixo índice de facticidade e alta intenção de enganar as pessoas. Segundo os pesquisadores "[...] ao contrário da paródia, não há compreensão implícita entre o autor e o leitor que o item é falso [...]" (TANDOC; LIM; LING, 2017, p. 143, tradução nossa) ${ }^{5}$.

Durante a campanha eleitoral de 2018 o "kit gay" foi uma das fake news na categoria fabricação que mais influenciou o debate político. ${ }^{6}$ O termo "kit gay" é o apelido pejorativo cunhado pela bancada conservadora do Congresso Nacional ao caderno "Escola Sem Homofobia" produzido pelo programa "Brasil Sem Homofobia", elaborado pelo Ministério da Educação, então gerido pelo petista de Fernando Haddad, em 2008. A proposta do "kit gay" era oferecer conhecimento e formação para que professores pudessem enfrentar situações de violência e preconceito contra alunos LGBT, assim como proporcionar o respeito à diversidade. Na época, a proposta foi rechaçada pela bancada conservadora e o governo do ex-presidente Lula acabou recuando.

Nas eleições de 2018 o assunto voltou a ser explorado após uma entrevista ao Jornal Nacional da Rede Globo, quando o então candidato Jair Bolsonaro (PSL) apresentou o livro infantil Aparelho Sexual e Cia (Hélène Bruller e Philippe Chapuis) como sendo um exemplar do "kit gay" e afirmou se tratar de uma ação do PT para ensinar a "Ideologia de Gênero" e despertar o desejo sexual nas crianças brasileiras. Além de não se tratar do referido caderno "Escola Sem Homofobia", o livro jamais foi distribuido nas escolas públicas brasileiras. No entanto, o presidenciável ultradireitista já havia se aproveitado do espaço de ampla audiência para fazer reverberar a notícia falsa contra o seu principal adversário, Fernando Haddad (PT).

A categoria "Manipulação" é apontada pelos estudiosos como sendo uma edição deliberada do fato para criar uma falsa narrativa em forma de notícias visuais que podem ser compostas por imagens, vídeos ou áudios cujo índice de facticidade é baixo ou nulo, mas com alta intenção de ludibriar. Os autores observaram que a manipulação audiovisual tornou-se recorrente graças à existência de poderosos softwares capazes de criar dos mais simples até os mais complexos efeitos, além de "[...] ajustes simples que podem incluir o aumento da saturação de cores, a remoção de elementos secundários, mudanças mais invasivas com a remoção ou a inserção de pessoa ou objeto em uma imagem [...]" (TANDOC; LIM; LING, 2017, p. 144, tradução nossa).?

Uma imagem manipulada que repercutiu nas redes sociais virtuais durante a campanha dava conta da candidata a vice-presidente na chapa petista, Manuela d'Ávila (PC do B), vestida com uma camiseta preta com os dizeres "Jesus é travesti", contendo um arco-íris em analogia ao movimento LGBT, em lugar da expressão original "Rebele-se". Aliado a essa grotesca adulteração, durante o periodo eleitoral, circularam inúmeras imagens editadas nas quais Manuela d'Ávila aparecia em supostos cultos satânicos, em situações de abuso de crianças e ao lado de mulheres, em uma insinuação à sua orientação sexual, com o objetivo de reforçar a narrativa de "libertinagem" da então candidata a vicepresidente e, assim, atenuar o apoio junto ao segmento evangélico e conservador.

Esses dois relatos são apenas algumas das inúmeras fake news que dominaram as eleições presidenciais brasileiras e corroboram com a implementação de estratégias de manipulação e fabricação de dados, amplamente utilizada nas grandes guerras do início do século $X X$. Como lembra D'ancona (2017) as campanhas de desinformação preparam terreno para a era da pósverdade, semeando a dúvida junto à opinião pública.

Assim, nestes tempos em que a liberdade de expressão tem sido "subjetivada" para sustentar opiniões, as redes sociais virtuais se configuraram

\footnotetext{
Do original: Unlike parody, there is no implicit understanding between the author and the reader that the item is false.

Disponivel em: https://www.valor.com.br/politica/5965577/estudo-diz-que-90-dos-eleitores-de-bolsonaro-acreditaram-em-fake-news. Acesso em: 20 jun 2019.

7 Do original: Simple adjustments can include increasing color saturation and removing minor elements. More-invasive changes can include removing or inserting a person into an image.
} 
como espaços de circulação de falsas verdades em uma via de mão-dupla que transcende do espectro virtual para o real, tal qual o inverso. Cabe pontuar que a internet, notadamente as redes sociais virtuais, não podem ser consideradas como responsáveis pelo surgimento das fake news. Em virtude das facilidades comunicativas possibilitadas pelo ciberespaço, a internet potencializou e ampliou as possibilidades de circulação das fake news. Nesse ambiente, as verdades universais são abandonadas e novas verdades e crenças compartilhadas instantaneamente baseadas em frases de efeito e imagens em formatos de "meme".

\section{E essa tal de pós-verdade?}

Passados longos 70 anos da ficcionalidade presente na obra 1984, de George Orwell, os elementos do futuro distópico estão por toda a parte atrelados aos mais variados dispositivos tecnológicos. No mundo da Oceânia, primeiramente, a verdade é desconsiderada e exterminada, em seguida a liberdade é sepultada. Nesta época de enaltecimento da opinião e da crescente necessidade de sustentar crenças pessoais, mesmo que os fatos objetivos as refutem, vimos emergir o fenômeno cuja emoção prevalece sob a razão, vitimizando diretamente o conceito da verdade, que já se encontrava em dissolução desde que as teorias pós-modernas emergiram com os estruturalistas em meados do século XX.

Na contemporaneidade, a acentuada revolução infocomunicacional tem sido marcada por controversos aspectos que afetam a sociabilidade, e as redes sociais virtuais têm sem comportado muito mais do que a função de comunicação cooperativa ao se converterem em megafone capaz de amplificar as vozes de sujeitos antes limitados a receptores de informações em uma audiência uniforme. Os sujeitos adquiriram "vozes" para falar o que bem compreendem e dedos para compartilhar o que julgam verdadeiro e correto. Com isso, a verdade é relativizada, ao passo que cada sujeito tem o poder de escolher uma realidade, em uma espécie de "self-service" e compartilhar a versão própria do fato ao ponto de esvair do imaginário popular a expressão "dono da verdade". Neste cenário de indiferença com a verdade cujo "especialista" fala o que quer, não há mais uma verdade absoluta, mas verdades ou meias-verdades

Não se trata de relevar a narrativa de superação da noção clássica da verdade, aceitar a meiaverdade ou normatizar a mentira, mas de considerar possivel novas semânticas para uma realidade que se altera na velocidade dos megabytes. Na vida digital, a verdade não é apenas o oposto do falso, mas cada vez mais o falso está se tornando uma verdade. Com efeito, em 2016, ascendeu a era da pósverdade ("posttruth"), adjetivo escolhido pelo Departamento da Universidade de Oxford, no Reino Unido, cujo emprego teve um pico e se elevou a $2000 \%$ por ocasião das eleições presidenciais norte-americanas e da campanha pela saída da Grã Bretanha da União Europeia, momento conhecido como Brexit. A terminologia, conforme definida pelo dicionário da Universidade de Oxford, se refere a "circunstâncias nas quais os fatos objetivos têm menos influência para definir a opinião pública do que o apelo à emoção ou às crenças pessoais" (OXFORD ENGLISH DICTIONARY, [2016]).8

O Dicionário de Oxford destacou que o termo pós-verdade não seria nenhuma novidade e o uso da palavra havia sido registrado pela primeira vez no ano de 1992, quando, em reflexão às guerras do Irã e do Golfo Pérsico, o dramaturgo sérvioamericano, Steve Tesich, cunhou a expressão na revista The Nation, para se referir ao fato de que o povo livre daquele periodo havia decidido por viver em um mundo de pós-verdade. A utilização do prefixo "pós-" estava em expansão e, em vez de apenas mencionar tempo posterior a um evento histórico como pós-guerra, passou a se referir a um tempo em que o conceito especificado perdeu a importância. Tesich asseverou o entendimento de que a própria verdade se 
tornou irrelevante e, à vista disso, a pós-verdade estendeu a compreensão da qualidade isolada de afirmações particulares para uma caracteristica dominante da época.

Na pós-verdade os sujeitos apelam às falsas argumentações em uma espécie de balão de ensaio, criando o que D'ancona (2017) intitulou como sendo "hiper-realidade", ou seja, o desaparecimento do hiato no modo discursivo entre o real e o imaginário. Na perspectiva pós-verdadeira o que é real é apenas imaginação e o imaginário se torna real e o direito de opinião se transforma em direito de criar percepções individualizadas do fato. As evidências não são suficientes para refutar essa perspectiva porque a pós-verdade é, sobretudo, um fenômeno emocional que contesta o próprio sentido de verdade.

Dentre os pensadores que se debruçam a compreender a era da pós-verdade, no Brasil, os postulados apresentados por Christian Dunker (2017) enriquecem o debate na perspectiva da psicanálise ao localizar o verbete como uma reação ao pós-modernismo, isto é, a pósmodernidade é a condição ideológica que fez a pós-verdade emergir, se aproveitando de percepções sociais e do excesso de definições em termos como relativismo, multiculturalismo, igualitarismo, entre outros. Para ele, assim como a pós-modernidade ascendeu a discussão sobre a compreensão do sujeito moderno, a pós-verdade traz uma reflexão prática e política sobre o entendimento acerca da verdade e de sua suposta autoridade (DUNKER, 2017).

Para Christian Dunker (2017), os excessos da contemporaneidade não aposentaram a verdade, mas a tornaram uma mera coadjuvante, isto é, mais um elemento sem prerrogativa, sem força e sem potência eticamente transformativa. A verdade está agora inflada de subjetividade, mesmo sem a presença de sujeito, se confundindo com processos sociológicos de individualização, com prerrogativas estéticas do gosto e com a força politica das religiões (DUNKER, 2017). Atentamente ele observa que, do ponto de vista das relações intersubjetivas, a pós-verdade promove a recusa do outro e a cultura da indiferença e, diante de ameaças, reage com ódio e violência. Esse é o cenário no qual o Brasil ingressou nos últimos anos.

\section{0 neoconservadorismo e as facetas do ódio nas redes sociais virtuais nas eleições de 2018}

Antes restrita a pequenos grupos no submundo clandestino, à luz do fenômeno de expansão mundial, a extrema-direita brasileira se articulou e utilizando-se das ferramentas disponiveis no ciberespaço emergiu em um "coquetel de neoconservadorismo" (GOMES, [2018]) que aflorou sentimentos que até então se encontravam recolhidos. Sem demonstrar constrangimento em seus processos discriminatórios, os intolerantes da extrema-direita passaram a transitar livremente nas timelines das redes sociais virtuais e a extrapolar os limites das telas dos dispositivos móveis como portadores do "direito" de professar valores repugnantes.

Wilson Gomes (2018) pontua que essa mistura explosiva inclui em sua composição uma combinação de temas neoconservadores originadas do continente europeu, como a xenofobia e a islamofobia; dos Estados Unidos, como a retórica anticomunista, a defesa do armamento, a guerra cultural contra pautas liberais nos costumes e, finalmente, o caráter tupiniquim, baseado na convocação das Forças Armadas para a politica e na associação entre Direitos Humanos como defesa do crime e de bandidos (GOMES, [2018]).

Ao promover um diálogo com aspectos objetivos e subjetivos desse momento, Michel Löwy (2015) observa que, guardadas as diferenças conjunturais, o recente levante da extrema-direita é um fenômeno que só encontra precedentes nos anos de 1930. Na visão do sociólogo, algumas correntes da esquerda falharam ao adotar um raciocínio economicista e a enxergar o crescimento da extrema-direita apenas como um efeito colateral da crise e do desemprego, desconsiderando fenômenos como a ascensão do fascismo e a consequente ofensiva ideológica de caráter racista, xenofóbica e nacionalista. 
Löwy (2015) aponta que o crescimento da extrema-direita ocorreu primeiramente devido ao processo de globalização capitalista neoliberal eà consequente produção de identity panics (pânicos de identidade), cuja obsessiva procura por fonte e raizes levou a "[...] formas chauvinistas de religião, de nacionalismo, além de alimentar conflitos étnicos e confessionais [...]" (LÖWY, 2015, p. 656-657). Em seguida, elenca a crise econômica de 2008, que despedaçou a Europa e o mundo e, por fim, cita a conjuntura internacional, particularmente, no Oriente Médio, na qual os eventos negativos foram habilmente aproveitados pela extrema-direita para promover a agenda conservadora.

Com relação ao Brasil, Löwy (2015) ressalta que a extrema-direita atual se difere da direita fascista da primeira metade do século XX, apesar da demagógica manipulação promovida por ambas ao se recorrer à luta contra a corrupção. No entanto, as extremas-direitas dos tempos distantes se aproximam em temas de agitação sociocultural, na ideologia repressiva do culto à violência policial, na intolerância contra minorias ou no apelo à ordem via intervenção militar.

As especificidades do neoconservadorismo à brasileira também são analisadas por Luis Felipe Miguel (2018) que as distribui em três vertentes: libertarianismo, fundamentalismo religioso e reciclagem do antigo anticomunismo (MIGUEL, 2018). A ideologia libertariana ou ultraliberal descendente da escola econômica austríaca chegou ao Brasil através de acadêmicos e de ativistas dos Estados Unidos pregando o Estado Mínimo e a rejeição a qualquer tipo de solidariedade social. O fundamentalismo religioso resultante do crescimento das igrejas neopentecostais e a inflexão dos seus líderes para a política fundamentado na "[...] percepção de que há uma verdade revelada que anula qualquer possibilidade de debate [...]" (MIGUEL, 2018, p. 21). Finalmente, a terceira vertente materializada na reciclagem do anticomunismo da Guerra Fria transformado em "bolivarianismo venezuelano" gerando uma sobreposição entre anticomunismo e antipetismo.

No Brasil, as recentes transformações na estrutura das classes sociais são particularidades que endossaram a acentuada reação da extrema-direita. Ao passo que as politicas compensatórias distributivas dos governos petistas melhoraram o padrão de vida das classes populares, a classe média defendeu-se para conter a migração social, manter a hierarquia social e salvaguardar seus privilégios. A classe abastarda reagiu manifestando intolerância política instrumentalizada na disseminação do ódio que recusa o diálogo e, por vezes, se efetiva no aniquilamento do que visualiza como inimigo.

Em artigo publicado no site da revista Le Monde Diplomatique Brasil, Camila Rocha (2017) relata que a nova direita se constituiu conectada via internet a partir da segunda metade dos anos 2000, periodo em que começaram a surgir novas organizações ultraliberais. Segundo a autora, utilizada por jovens universitários e profissionais de diversas áreas entusiasmados com as ideias do liberalismo econômico, a internet facilitou o surgimento de comunidades e o encontro de pessoas. Assim, conforme Rocha (2017), "[...] em poucos anos se formaram na rede social grupos mais coesos que compartilhavam o mesmo entusiasmo por uma versão radical do que o liberalismo defendido pelos think tanks existentes até então: o libertarianismo, ou ultraliberalismo [...]" (ROCHA, [2017]).

Na prática, esses grupos ascenderam junto com a onda neoconservadora configurada em um leque de novas feições. Silvio Almeida (2018) no capitulo da obra O ódio como Politica descreve que neoconservadorismo é uma ideologia surgida na década de 1960 em reação aos fenômenos pósSegunda Guerra Mundial como o Welfare State (Estado do bem-estar-social), a contracultura e a nova esquerda, assim como o advento do modelo de acumulação fordista. Os neoconservadores buscavam preservar a ordem social mantendo as diferenças de classe, de sexo e de raça em oposição a uma suposta degradação cultural da sociedade sem classe infestada de hippies, sindicalistas, comunistas, negros, feministas entre outros agrupamentos que alegam terem ganhado força em razão da permissividade e do assistencialismo estatal (ALMEIDA, 2018).

Por sua vez, o neoconservadorismo do século 
XXI carrega o aglomerado ideológico da direita posterior às grandes guerras acrescido de um "antiglobalismo", da retórica da violência e a consequente naturalização do discurso de ódio, da rejeição ao politicamente correto e da repulsa aos princípios que norteiam a democracia liberal. Ademais, o grande diferencial do neoconservadorismo conforme Almeida (2018) é a sua capacidade em atender aos preceitos do processo de radicalização do neoliberalismo com "desdemocratização" para possibilitar o aprofundamento de políticas de austeridade e a retirada de direitos.

Nos tempos atuais, os intolerantes revelaram um cenário de barbárie se agarrando ao manto da liberdade de expressão para requererem o direito de expressar e legitimar discursos de ódio contra minorias e vulneráveis sociais. Assim, a intolerância politica se tornou o terreno onde o ódio brotou, cuja razão absoluta faz o intolerante acreditar em uma visão ideal de mundo. Essa intolerância pode ser compreendida como uma irracionalidade (de indivíduos supostamente superiores) que nega a alteridade do outro (supostamente inferiores) resultante do medo decorrente de ameaças. É um comportamento impaciente que busca manter indivíduos ou grupos com valores divergentes isolados por meio da diminuição e do desprezo. Para os intolerantes, o diferente não deve ser tolerado porque rompeu com pactos sociais, fugiu à naturalidade dos fenômenos da sociabilidade e se tornou um doente impossivel da convivência social.

Para Mirian Aquino (2001) a intolerância é uma reação de sujeitos que julgam terem seus projetos de vida ameaçados e, decorrente dessa concepção, implica atentar que intolerância não é a ausência de informação, ao contrário, ela é reflexo de uma informação deformada. Ao discutir os efeitos danosos da intolerância, Aquino (2001) considera que essa prática "[...] minimiza, retarda, compromete e nega o desenvolvimento dos individuos. Ela obstrui, interdita, exclui, seleciona e nega a troca. A linguagem da intolerância é a violência. O ódio, que aniquila a liberdade de homens e mulheres, é o prolongamento dela [...]" (AQUINO, 2001, p. 3). A intolerância é ainda capaz de negar o rico potencial da informação, esvaziar o seu significado e aprisionar o indivíduo em um mundo de desinformação (AQUINO, 2001).

Por seu turno, a conjuntura política recente decorre de disseminação do discurso de ódio em meio a uma difusa conjuntura preenchida por um julgamento sumário provocador de rupturas nas esferas da sociabilidade após as Jornadas de Junho de 2013. Apesar das inúmeras análises sobre os significados das Jornadas de Junho, os estudos são unânimes quanto à importância desse evento para o rumo político do Brasil. Jessé Souza (2016, 2017), por exemplo, argumenta que as decantadas Jornadas de Junho possibilitaram uma nova narrativa para a direita e seu público.

Conforme Souza (2016, 2017), a rápida ascensão social das classes populares durante os governos petistas (2003-2013) criou um medo generalizado na classe média que viu os seus espaços exclusivos ameaçados e ansiava travestir o ódio e o desprezo de classe. Faltava então, uma narrativa adequada para operacionalizar o irracional discurso e um lider carismático encontrados, respectivamente, na Operação Lava Jato com o seu "[...] moralismo típico do combate seletivo à corrupção[...]" (SOUZA, 2016, p. 86) e no juiz Sérgio Moro com sua estética e moral.

Na esteira das pós-manifestações de 2013 surgiram os grupos ditos apartidários como o Movimento Brasil Livre, Revoltados Online, Vem Pra Rua, entre outros, que tiveram papel fundamental na ascensão da nova extrema-direita brasileira e nas manifestações pró-impeachment. Desde então, o Brasil passou a registrar protestos centrados no discurso da moralidade seletiva de combate à corrupção política, na defesa da meritocracia, no combate às regalias dos "vagabundos" beneficiários do programa BolsaFamilia e na nostalgia ao "meu país de volta". Simultaneamente, a extrema-direita com sua retórica da violência rebaixou o debate público e inundou as redes sociais virtuais de fake news e memes fundados em uma linguagem vulgar com o propósito de moldar o comportamento das massas em uma espécie de vírus que reverberou em diferentes camadas sociais. 
Com efeito, a extrema-direita manifestou sua intolerância, xenofobia, naturalizou o racismo e a homofobia, e transformou o discurso de ódio em estratégia política exitosa em face do resultado eleitoral alcançado em 2018. O obscurantismo durante as eleições ocorridas em 2018, se confirmou quando a candidatura da extrema-direita absorveu o sentimento antipolítica construido ao longo dos últimos anos e forjou um posicionamento alinhado aos interesses do povo brasileiro contra as demais candidaturas consideradas representantes do establishment "corrupto explorador" do povo trabalhador. Em um jogo de encenação, as forças neoconservadoras conseguiram convencer uma grande parcela da população brasileira que os sucessivos governos desde a redemocratização do país na década de 1980 foram de esquerda e representavam a face do "sistema" que precisava ruir.

Inegavelmente, o ciberespaço foi transformado em um ambiente de disseminação do discurso de ódio promovido pela extrema-direita. Segundo revelou a Organização Não Governamental SaferNet que atua na promoção dos Direitos Humanos na internet, em reportagem publicada na BBC Brasil, ${ }^{9}$ o número de denúncias relacionadas à intolerância e discurso de ódio mais que dobrou durante o periodo oficial da campanha de 26 de agosto a 28 de outubro de 2018 registrando 39.316 casos comparados aos 14.563 anotados entre 1 . $^{\circ}$ de julho e 6 de outubro de 2014. Do volume total anotado em 2018, 13.999 denúncias foram relacionadas somente ao discurso de ódio.
Os dados do levantamento mostram que apenas no $2 .^{\circ}$ turno da eleição presidencial de 2018, as denúncias com teor de "[...] xenofobia cresceram $2.369 .5 \%$, de apologia e de incitação a crimes contra a vida, 630,52\%, de neonazismo, $548,4 \%$, de homofobia, 350,2\%, de racismo, $218,2 \%$, e de intolerância religiosa, 145,13\% [...]" (MESQUITA, 2018), majoritariamente oriundas do Facebook. Enquanto no dia da votação em primeiro turno foram registradas 109 denúncias de xenofobia, no dia seguinte esse número aumentou 46 vezes e chegou a 5.163 casos denunciados. Conforme o relatório da ONG, o estrondoso crescimento de manifestações xenófobas ocorreu devido à expressiva votação que a população nordestina proferiu ao candidato petista, Fernando Haddad, impossibilitando a vitória do candidato da extremadireita, Jair Bolsonaro, ainda no primeiro turno.

Apesar de não representar a totalidade do que ocorreu no período da campanha eleitoral, já que a ONG apenas recebe denúncias de pessoas dispostas a acessar a plataforma, além de existir outros canais de denúncias, o levantamento, entretanto, corrobora para constatar o cenário visualizado nas redes sociais virtuais naquele momento histórico. Como ilustração de manifestação xenófoba, na sequência, desenvolvemos a análise do discurso com base em categorias da Teoria Semiolinguística, de Patrick Charaudeau. Analisamos o corpus constituido pelo comportamento linguageiro nas maneiras de dizer de um sujeito-internauta com o objetivo de aprofundar a compreensão sobre como o discurso político de ódio utilizado pela extremadireita reverberou na rede social virtual Facebook. 
Figura 1 - Reação-discursiva do sujeito internauta manifestando xenofobia

Eliane

\section{Cantanhêde}

@elianecantanhedejornali sta

Página inicial

Sobre

Fotos

Publicações

Comunidade

Informações e anúncios

A Eliane Cantanhêde 23 de setembro de 2018 .

Dois Brasis: direita sólida no Sul e no Centro-Oeste, esquerda reinando no Nordeste. https://politica.estadao.com. br/.../eleicoes,os-dois-brasis, 7 ..

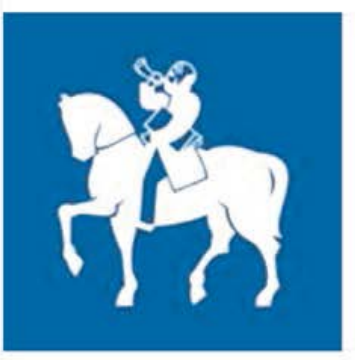

(1) $=206$
255 comentários 43 compartilhamentos

Comentar
Compartilhar

\section{POLITICA.ESTADAO.COM.BR}

\section{Os dois Brasis - Política - Estadão}

Direita solidamente no Sul e Centro-Oeste, esquerda definitivamente no Nordeste

\section{Curtir}

O Centro-oeste é direita pq foi colonizado em grande parte por sulistas. Somos herdeiros do pragmatismo realista daqueles que lutaram quase a vida inteira para formar e manter suas fronteiras contra a invasão dos castelhanos. O Nordeste sempre buscou um reino encantado idilico como escape das angústias do presente. Veja como o que digo é verdade, pega o livro mais importante do gaúcho o Tempo e Vento (Érico Verissimo) e compara com a obra do grande Suassuna à Pedra do Reino. O primeiro conta uma história crua, pragmática sem misticismo, sem magia. A segunda é mágica, cheia de coisas mirabolantes que tentam, sem muito sucesso, esconder o sofrimento do sertão. O mote da primeira diz que sofrer é preciso. Já a segunda fala que imaginar é preciso. Por isso um grupo é de direita e outro de esquerda. Um grupo não sabe sonhar e outro só sabe sonhar.

Curtir - Responder $\cdot 1 \mathrm{~d} \cdot$ Editado

Fonte: Captura de tela do Facebook.

Durante o periodo eleitoral a jornalista Eliane Cantanhêde utilizou a sua página no Facebook para compartilhar links dos artigos de análise política escritos para o jornal O Estado de $S$. Paulo e disponibilizados no site do veículo a qual ela submetia o serviço intelectual de analista. Faltando 15 dias para a votação em primeiro turno ela postou o artigo intitulado "Dois Brasis: direita sólida no Sul e no Centro-Oeste, esquerda reinando no Nordeste" (Figura 1) em que, na condição de comentarista, examinava os números revelados pela pesquisa de intenção de votos realizada pelo Instituto Datafolha, publicada dias antes. No ato de linguagem, considerado apenas o título do artigo, uma vez que a jornalista não produz qualquer escrita na postagem além da reprodução do próprio título do artigo, a locutora adota o modo enunciativo recorrendo a um comportamento elocutivo para enunciar opinião acerca dos números da pesquisa.

O ponto de vista da jornalista reúne uma mescla dos pontos de vista "modo de saber" e "avaliação" (CHARAUDEAU, 2016a), pois nele estão presentes elementos que, por um lado, especificam o conhecimento dela sobre um determinado propósito e, por outro, especificam o julgamento dela sobre o referido propósito. Como bem observa Charaudeau (2016a), o comportamento elocutivo ocorre quando o locutor expressa seu ponto de vista, configurando-se linguisticamente através de categorias modais especificas.

Desempenhando o seu papel de locutora, a jornalista reconhece o fato e busca relatá-lo de maneira objetiva para não ser implicada no que é dito. Aparentemente, atende aos principios requeridos pelo jornalismo para criar efeitos de 
objetividade e de imparcialidade, no entanto, o título demonstra que a locutora utiliza do recurso de construção de sentidos cuja intencionalidade é provocar o julgamento do fato pelos seguidores da página. Nesse sentido, é possivel constatar que o sujeito-internauta ativa seus conhecimentos linguísticos, reúne informações acerca do fato na construção dos sentidos sobre o enunciado e, desse modo, seduz a audiência constituída pelos demais seguidores da página e leitores da postagem.

O sujeito-internauta ativa o procedimento discursivo de comparação presente no modo argumentativo a fim de produzir efeitos de persuasão e reforçar o seu julgamento fundado na dicotomia da superioridade dele (região) sobre a inferioridade dos nordestinos. Ele recorre à categoria de qualificação para apresentar as caracteristicas das respectivas regiões, uma formada por trabalhadores, localizados no espectro político à direita, e outra constituída por "sonhadores", situados no espectro político à esquerda para, desta maneira, destacar as dessemelhanças existentes entre elas, notadamente no aspecto sociocultural.

Apesar da tentativa de ocultar o insulto aos nordestinos, o enunciado do sujeito-internauta revela uma patologia social grave supostamente organizada em uma lógica argumentativa distribuída em asserção de partida (A1), em asserção de chegada (A2) e em asserção de passagem (CHARAUDEAU, 2016a). Assim, o sujeito-internauta utiliza o fragmento IO Centrooeste é direita pq foi colonizado em grande parte por sulistas] como premissa e o trecho [Por isso um grupo é de direita e outro de esquerda. Um grupo não sabe sonhar e outro só sabe sonhar] para legitimar e concluir o raciocínio.

O sujeito-internauta virtualiza um quadro comparativo de duas importantes obras da literatura brasileira como asserção de passagem para justificar que IO Nordeste sempre buscou um reino encantado idilico como escape das angústias do presente] por ser uma região [mágica, cheia de coisas mirabolantes que tentam, sem muito sucesso, esconder o sofrimento do sertãol. Logo, o universo de crença desse sujeito-internauta tenta estabelecer a prova de que regiões que não sonham, votam na direita e são superiores, enquanto a região Nordeste, por ser sonhadora e por votar na esquerda, é considerada como inferior.

Cabe ainda observar que ao enunciar sua posição de concordância, o sujeito-internauta tenta construir um ethos intelectual (imagem de si), afinal, é um herdeiro do pragmatismo realista dos sulistas. Entretanto, o sujeito-internauta omite que o processo de independência do Brasil foi iniciado com as inúmeras revoluções registradas no litoral nordestino, notadamente a Revolução Pernambucana e a Independência da Bahia.

\section{Considerações finais}

Nos tempos atuais, a pós-verdade tem contribuido para reconfigurar do sentido de uma Opinião Pública racional que ao ser desconectada das relações sociais, em especial, a política, tem levado os individuos a tomarem decisões sem os esclarecimentos necessários. Essa reconfiguração, reflexo do ódio e da intolerância, ao lado do fanatismo, do medo, da suspeita, da discrição e da mentira, como enumera Walter Lippman (2008), são considerados os sete pecados mortais contra a Opinião Pública que silenciosamente acompanha o aniquilamento do apelo à razão.

Também tem contribuido para reconfigurar o sentido da vida política, quer seja na instância de poder ou na instância cidadã/opinião (CHARAUDEAU, 2016b), já que para alcançar o poder é necessário conquistá-lo pela palavra (CHARAUDEAU, 2016b), isto é, antes de alçar o poder é preciso convencer pelo argumento. Ora, para convencer um individuo a tomar uma decisão, neste caso a votar em um candidato, é fundamental que ele esteja plenamente esclarecido acerca dos fatos. No entanto, a pós-verdade mergulha o sujeito naquilo que Charaudeau (2016b) considera como sendo "saber de opinião".

O linguista francês argumenta que a manipulação das mentes ocorre pela linguagem e a opinião é um fato de linguagem resultante do entrecruzamento de atos linguageiros que o indivíduo ou um coletivo recebeu, ouviu e 
produziu. Por conseguinte, para esse estudioso, a manipulação seria uma visada discursiva de incitação com a finalidade de influenciar o interlocutor a "fazer-agir". Desta maneira, a extrema-direita brasileira utilizou do apelo à emoção e às crenças pessoais enquanto estratégia política para conquistar mentes e corações. As fake news foram proliferadas nas redes sociais virtuais não apenas para insuflar ânimos, mas também para suscitar o preconceito, o ódio e a intolerância de modo a influenciar os resultados das eleições em 2018.

As discussões e os dados apresentados demonstram o clima virulento que abateu as redes sociais virtuais nos últimos anos, notadamente no período da campanha eleitoral brasileira. 0 panorama neoconservador acarretou conflitos que extrapolaram os limites das telas dos dispositivos móveis, provocou rompimentos de relacionamentos e moldou o sistema de valores que circulam na sociedade pela introdução do ódio como estratégia política. Por fim, levou o Brasil a um obscurantismo programático.

\section{Referências}

ADORNO, Theodor. Educação e emancipação. Rio de Janeiro: Paz e Terra, 1995.

ALMEIDA, Silvio Luiz de. Neoconservadorismo e liberalismo. In: GALLEGO, Esther Solano (org.). O Ódio como Politica: a reinvenção da direita no Brasil. São Paulo: Boitempo, 2018. p. 27-32. v. 1.

AQUINO, Mirian de Albuquerque. A informação nas estratégias educativas de recusa à intolerância em contextos virtuais/reais. BOCC/Biblioteca Online de Ciências da Comunicação, 2001. p. 1-16. v. I. v. I.

CASTELLS, Manuel. A sociedade em rede. 12. ed. São Paulo: Paz e Terra, 2009.

CHARAUDEAU, Patrick. Linguagem e discurso: modos de organização. Tradução de Angela M. S.Corrêa. 2. Ed. São Paulo: Contexto, 2016a.

CHARADEAU, Patrick. A conquista da opinião pública: como o discurso manipula as escolhas politicas. Tradução de Angela M. S.Corrêa. São Paulo: Contexto, 2016b

D'ANCONA, Matthew. Pós-Verdade: a nova guerra contra os fatos em tempos de fakenews. Trad. de Carlos Szlak. Barueri: Faro Editorial, 2018.

DUNKER, Christian et al. Ética e Pós-verdade. Porto Alegre: Dublinense, 2017.
GOMES, Wilson. Antipetismo, neoconservadorismo e "novos participantes" nas eleições de 2018. Revista Cult. 12 abr. 2018. Disponivel em: https://revistacult. uol.com.br/home/antipetismo-neoconservadorismo-e-novos-participantes-nas-eleicoes-de-2018/. Acesso em: 02 maio 2019.

KIRBY, Emma Jane. A cidade europeia que enriquece inventando notícias e influenciando eleições. $B B C$ News, 12 dez. 2016. Disponivel em: https://www.bbc. com/portuguese/internacional-38206498. Acesso em: 09 abr. 2019.

\section{LÉVY, Pierre. Cibercultura. São Paulo: Editora 34, 1999}

LIPPMANN, Walter. Opinião Pública. Trad. De Jacques A. Wainberg. Petrópolis: Vozes, 2008.

LÖWY, Michael. Conservadorismo e extrema-direita na Europa e no Brasil. Serv. Soc., São Paulo, n. 124, p. 652-664, out./dez. 2015. https://doi. org/10.1590/0101-6628.044

MARCONDES FILHO, Ciro. O capital da noticia: jornalismo como produção social da segunda natureza. São Paulo: Ed. Ática, 1989.

MESQUITA, Lígia. Denúncias de discurso de ódio online dispararam no $2^{\circ}$ turno das eleições, diz ONG. BBC Brasil, og nov. 2018. Disponivel em: https:// www.bbc.com/portuguese/brasil-46146756. Acesso em: 21 maio 2019.

MIGUEL, Luis Felipe. A reemergência da direita brasileira. In: GALLEGO, Esther Solano (org.). O Ódio como Política: a reinvenção da direita no Brasil. São Paulo: Boitempo, 2018. p. 17-26. v. 1.

PASQUINI, Patricia. Estudo diz que 90\% dos eleitores de Bolsonaro acreditaram em fake news. Disponivel em: https://www.valor.com.br/politica/5965577/estudo-diz-que-9o-dos-eleitores-de-bolsonaro-acreditaram-em-fake-news. Acesso em: 21 jan. 2019.

ORWELL, George. 1984. Trad. de Alexandre Hubner e Heloisa Jahn. São Paulo: Companhia das Letras, 2009.

OXFORD ENGLISH DICTIONARY. Word of the year 2016 is.... Disponivel em: https://en.oxforddictionaries.com/word-of-the-year/word-of-the-year-2016. Acesso em: 17 abr. 2019.

ROCHA, Camila. O jogo sujo da direita: think tanks ultraliberais e a nova direita brasileira. Le Monde Diplomatique Brasil, 2 nov. 2017. Disponivel em: https:// diplomatique.org.br/think-tanksultraliberais-e-nova-direita-brasileira/. Acesso em: 16 dez. 2019.

SOUZA, Jessé. A elite do atraso: da escravidão à lava-jato. Rio de Janeiro: Leya, 2017.

SOUZA, Jessé. A radiografia do golpe. Rio de Janeiro: Leya, 2016.

TANDOC JUNIOR, Edson; LIM, Zheng Wei; LING, Richard. Defining fake news. Trad. Mauri de Castro Azevedo. Digital Journalism, Abingdon, v. 6, n. 2, p. 137-153, 2017. https://doi.org/10.1080/21670811.2017.1360143

WOLF, Mauro. Teorias da Comunicação. Lisboa: Presença, 1999 


\section{Mauri de Castro Azevedo ${ }^{1}$}

Discente do Programa de Pós-Graduação em Letras: Cultura, Educação e Linguagens da Universidade Estadual do Sudoeste da Bahia (UESB, Vitória da Conquista, BA, Brasil).

\section{Marcus Antônio Assis Lima ${ }^{1}$}

Doutorado em Estudos Linguísticos pela Universidade Federal de Minas Gerais (UFMG, Belo Horizonte, MG, Brasil), professor da Universidade Estadual do Sudoeste da Bahia (UESB) em Vitória da Conquista, BA, Brasil.

\section{Endereço para correspondência}

Mauri de Castro Azevedo/Marcus Antônio Assis Lima

Universidade Estadual do Sudoeste da Bahia - Campus de Vitória da Conquista

Programa de Pós-Graduação em Letras: Cultura, Educação e Linguagens

Estrada do Bem Querer, Km 04

45083-900

Vitória da Conquista, BA, Brasil 